\title{
Circumcision Compressive Dressing (CCD)
}

\section{ARTICLE INFO}

\section{Article Type}

Original Research

\section{Authors}

Rabani S.M. ${ }^{* 1} M D$

Mousavizadeh A. ${ }^{2} M D, P h D$,

Rabani S.H. ${ }^{3} M D$

Mosavi A. ${ }^{4} \mathrm{MSC}$

\section{How to cite this article}

Rabani S.M, Mousavizadeh A, Rab-

ani S, HMosavi A. Circumcision Co-

mpressive Dressing (CCD). Journal

of Clinical Care and Skills. 2020; 1(2):71-74
${ }^{1}$ Urology Department, Medical Faculty, Yasuj University of Medical Sciences, Yasuj, Iran

${ }^{2}$ Social Determinants of Health Research Center, Yasuj University of Medical Sciences, Yusuj, Iran

${ }^{3}$ Cellular \& Molecular Research Center, Yasuj University of Medical Sciences, Yasuj, Iran

${ }^{4}$ Medical Surgical Nursing Department, Nursing Faculty, Yasuj University of Medical Sciences, Yasuj, Iran

\section{Correspondence}

Address: Medical Faculty, Yasuj University of Medical Sciences, Shahid Jalil Street, Yasuj, Iran. Postal Code: 7591994799 Phone: +98 (74) 33230290 Fax: +98 (74) 33235153 Rabani.smr@yums.ac.ir

\section{Article History}

Received: October 6, 2017

Accepted: October 11, 2018

ePublished: June 20, 2020

\section{A B S T R A C T}

Aims Circumcision is a minor urologic surgery that is widely used in Iran and other Muslim and non-muslin countries. A common complication following this procedure is bleeding. The aim of this study was to compare compressive dressing with no dressing and conventional dressing options for circumcision in point of bleeding after circumcision.

Materials and Methods Between October 2010 and July 2016, 126 boys underwent elective circumcision by a single surgeon and in a single center (Beheshti Teaching Hospital, Yasouj University of Medical Sciences, Yasouj, Iran). The patients were allocated in 3 groups by simple randomization method. The method of procedure was the same in 3 groups. In group one (42 boys) conventional dressing, group 2 ( 42 boys) no dressing, and in group 3 ( 42 boys) compressive dressing was done. Patients were followed for one week and outcomes were recorded and compared. Data were analyzed by SPSS 19 software using one-way analysis of variance and chi squared tests.

Findings There was a significant difference between the group 3 and the other two groups in terms of post-operative bleeding $(\mathrm{p}=0.013)$. There were 15 reattendances for bleeding; 8 patients (19.0\%) in group one, 7 patients (16.7\%) in group 2 and no patients in group 3 , but all had minimal bleeding and no life- threatening bleeding was encountered.

Conclusion Bleeding is less by using compressive dressing compared to no dressing and conventional dressing in circumcision.

Keywords Male Circumcision; Bleeding; Complications

\section{I T A T I O N L I N KS}

[1] A review of the current state of the male circumcision literature [2] do motives matter in male circumcision? 'Conscientious objection' against the circumcision of a Muslim child with a blood disorder [3] Religious differences in female genital cutting: a case study from Burkina Faso [4] Complications of circumcision [5] Techniques of male circumcision [6] Complications of traditional circumcision amongst young Xhosa males seen at St Lucy's Hospital, Tsolo, Eastern Cape, South Africa [7] The new politics of male circumcision: HIV/AIDS, health law and social justice [8] Cultural circumcision in EU public hospitals - an ethical discussion [9] Male circumcision and sexual function in men and women: a survey-based, cross-sectional study in Denmark [10] Male infant circumcision as a 'HIV vaccine' [11] Counseling parents who are considering newborn male circumcision 


\section{Introduction}

Male circumcision is one of the most commonly performed surgical procedures worldwide and a subject that has been the center of considerable debate ${ }^{[1]}$. About one third of males in the world are circumcised and it is the most common surgical procedure in the United States today [2]. Although as a religious order male circumcision is mandatory for Muslim males in Islamic republic of Iran, it can be ignored in life threatening bleeding tendencies [2]. Female circumcision is also performed in some parts of the world, for example in Burkina Faso threequarter of adult females are circumcised [3]. There are numerous techniques for performing male circumcision, but in all of them the final mission is to remove the prepuce, by creating ischemia or cutting the prepuce directly. Morbidities and even in rare cases, mortalities have been reported for elective male circumcision [4]. The circumcision procedure has a number of complications, including bleeding, concealed penis, phimosis, Skin bridge, Urinary retention, infection, Fistulas, and necrosis. But one of the most common complications of circumcision is bleeding $[5,6]$. One of the ways to control bleeding in the surgical area is wound dressing.

The aim of this study was to compare our innovative dressing; compressive dressing; with no dressing and conventional dressing options for circumcision.

\section{Materials and Methods}

Between October 2010 and July 2016, 126 boys underwent elective circumcision by a single surgeon and in a single center (Beheshti Teaching Hospital, Yasouj University of Medical Sciences, Yasouj, Iran). In this procedure the foreskin or prepuce is cut from the glans penis directly by knife or by creating ring ischemia.

Informed consent was achieved from boy parents. The proposal of the study was in Yasouj University of Medical Sciences committee and approved by ethic code: IR.REC.1396.92.

All of our patients underwent circumcision by cutting the prepuce, hemostasis by electro cautery, and suturing by 5-0 chromic catgut in 4 points $(3,6$, 9 , and 12 O'clock). The patients were allocated in 3 groups by simple randomization method. In group one (42 boys) conventional dressing was done. In this method, after circumcision and performing sutures, the site was dressed with sterile gauze and some gentamicin ointment, and the dressing was kept for 3-5 days on the wound. Change dressing is done as needed. (Figure 1).

Group 2 (42 boys) no dressing (Figure 2) and in group 3 (42 boys) compressive dressing was done (Figure 3). In group 3, after suturing the wound, the compressive dressing comprises a piece of soft sponge that stained by gentamycin ointment and is placed on circumcised line of cutting and is fixed by the same sutures of the wound in above mentioned
4 points. Patients in 3 groups were followed for one week and outcomes were recorded and compared. The method of operation procedure was the same in 3 groups.

Data were analyzed by SPSS 19 software using oneway analysis of variance and chi squared tests.

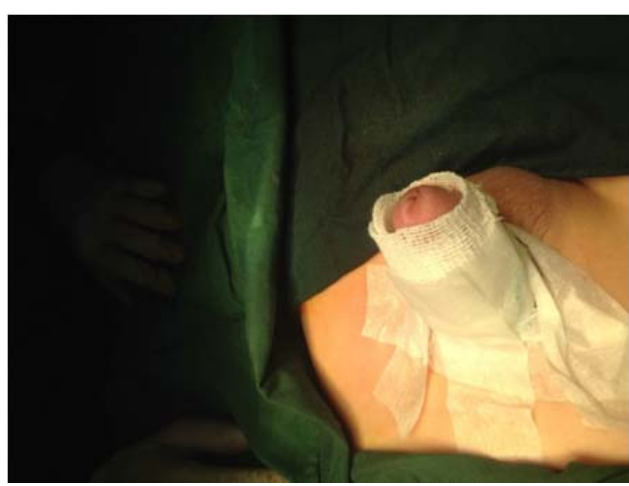

Figure 1) Conventional dressing

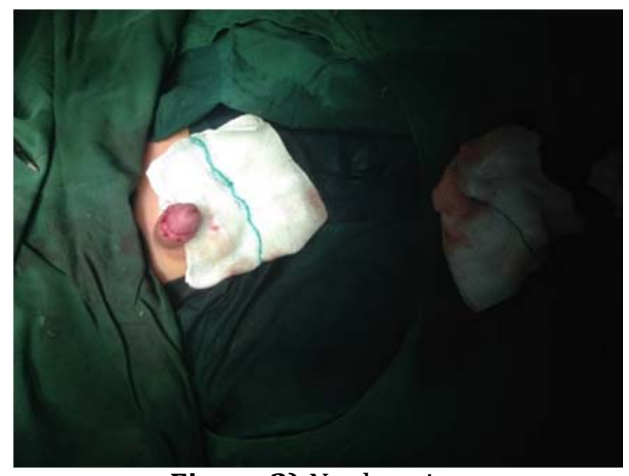

Figure 2) No dressing

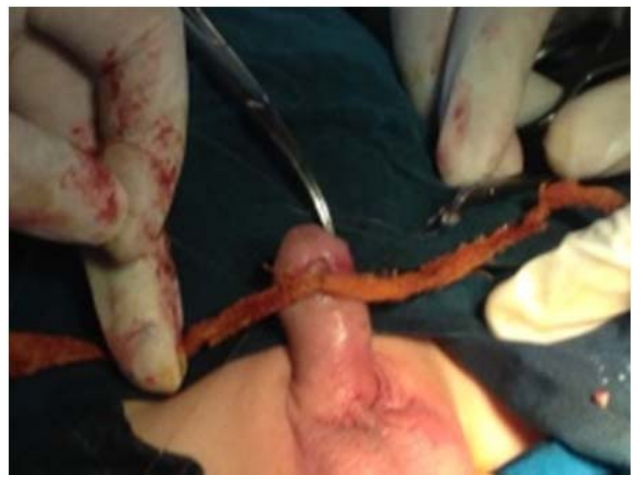

Figure 3-A) Suture at 6 o'clock

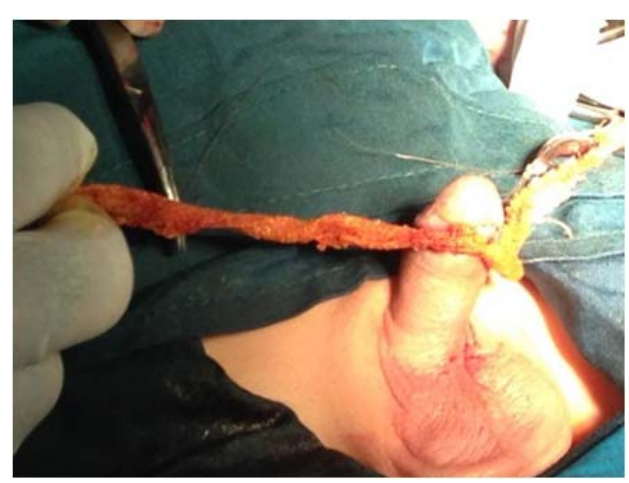

Figure 3-B) Sutures at 6 and 9 o'clock 


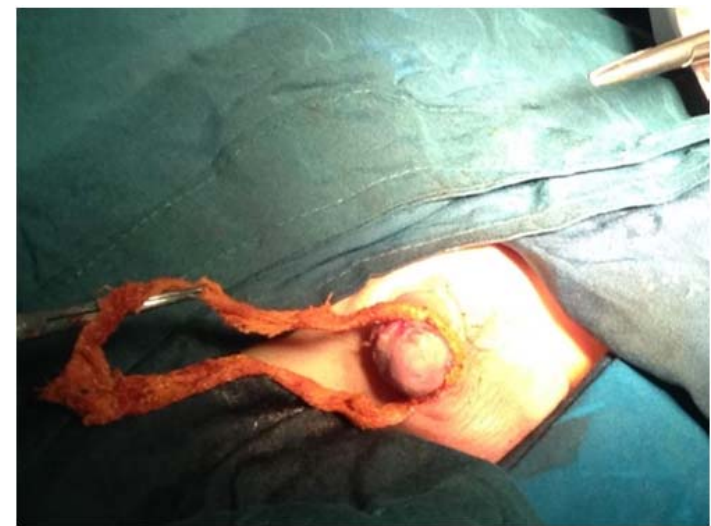

Figure 3-C) Sutures at 6, 9, and 15 o'clock

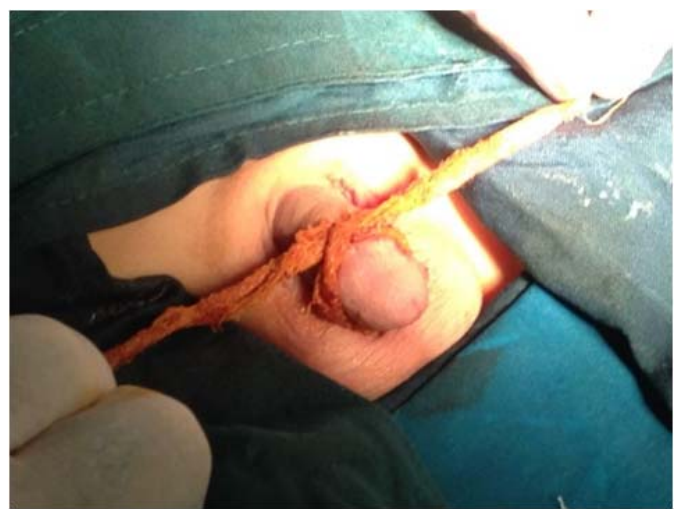

Figure 3-D) Sutures at 6, 9, 15, and 12 o'clock

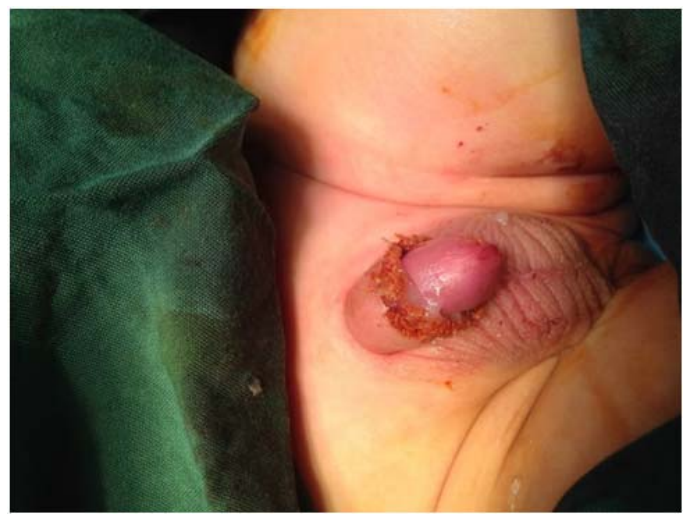

Figure 3-E) The final shape of innovative dressing

\section{Findings}

The means of age among three groups have no significance difference (Table 1).

For the purpose of circumcision, 115 (91.3\%) patients underwent general anesthesia and 11 $(8.7 \%)$ were under spinal anesthesia. There was no statistically significant difference among groups in terms of type of anesthesia (Table 2).

There was a significant difference between the group 3 and the other two groups in terms of postoperative bleeding $(p=0.013)$. There were 15 reattendances for bleeding; 8 patients in group one, 7 patients in group 2 and no patients in group 3 , but all had minimal bleeding and no life- threatening bleeding was encountered. All of the reattndances were managed conservatively (Table 3).
Table 1) The comparison of means of age among participants in study by using one-way analysis of variance

\begin{tabular}{lc|ccc}
\hline Groups & Mean of age (months) & N & F & p.value \\
\hline Group 1 & $39.83 \pm 3.68$ & 42 & & \\
Group 2 & $39.81 \pm 3.52$ & 42 & 1.6 & 0.206 \\
Group 3 & $47.50 \pm 3.30$ & 42 & & \\
Total & $42.38 \pm 2.03$ & 126 & & \\
\hline
\end{tabular}

Table 2) The comparison of frequency distribution of anesthesia type in 3 groups under study using chi square

test (the numbers in parentheses are percentage)

\begin{tabular}{lccc}
\hline \multicolumn{1}{c}{ Groups } & General & lumbar & p.value \\
\hline Group 1 & $40(95.2)$ & $2(4.8)$ & \\
Group 2 & $36(85.7)$ & $6(14.3)$ & 0.27 \\
Group 3 & $39(92.9)$ & $3(7.1)$ & \\
Total & $115(91.3)$ & $11(8.7)$ & \\
\hline
\end{tabular}

Table 3) The comparison of frequency distribution of bleeding in 3 groups under study using chi square test (the numbers in parentheses are percentage)

\begin{tabular}{l|c|c|c|c|c}
\hline Bleeding & Group 1 & Group 2 & Group 3 & Total & p.value \\
\hline No & 34 & 35 & $42(100)$ & 111 & \\
& $(81.0)$ & $(83.3)$ & & $(88.1)$ & 0.013 \\
Yes & $8(19.0)$ & $7(16.7)$ & 0 & $15(11.9)$ & \\
Total & $42(100)$ & $42(100)$ & $42(100)$ & $126(100)$ & \\
\hline
\end{tabular}

\section{Discussion}

Male circumcision is a common surgical procedure with different techniques of surgery and also different motives for performing. Although this procedure is being done as a religious duty in some countries, there are many medical explanations considering its benefits in preventive medicine. Really the incorporation of cultural circumcision into public health services is a kind of medicalization so that the procedure is now being promoted as a musicalized response to the HIV/AIDS pandemic in sub-Saharan Africa [7]. Albeit in a study by Robert Darby and Robert Van Howe, they concluded that circumcision is not a surgical vaccine and there is no case for boosting infant male circumcision to combat heterosexual transmission of HIV in Australia [8].

This procedure is rare in countries like Denmark [9] and Sweden [10], and in Germany, circumcision is unlawful in males less than 14 years of age.

Circumcision as a simple procedure and can be done out of the hospital, but experts support a utilitarian argument that finds hospital-based circumcision safer than non-medicalized alternatives.

About the age of performing circumcision there are controversies among experts. The American Academy of Pediatrics has a study about the health benefits of newborn male circumcision and finally recommended that the health benefits of newborn male circumcision exceed the risks [11]. We recommend elective circumcision to be done when anesthesia can be done safely and this depends on the facility of each medical center.

Selecting the type of anesthesia for circumcision is also an issue of considering. Although circumcision 
can easily be done under local anesthesia especially in newborns, caudal and general anesthesia can also be used. We recommend circumcision to be done under general anesthesia and in an age safe for anesthesia depending on the facility of the center. In this situation there is enough time and silence for hemostasis.

No specific limitation was encountered except for dealing with some parents in group 2, where no dressing was out of their expectations.

This method of circumcision dressing is viable both economically and medical. In order to ensure the generalization of the results of this study, it is suggested that more interventional studies be conducted with more samples.

\section{Conclusion}

With every aim of performing, selecting a familial technique of surgery, and having a sufficient course of training, circumcision has minimal danger of bleeding in experienced hands.

Acknowledgements: The authors have to acknowledge the operation room personnel in Beheshti Teacing Hospital for their cooperation in performing the procedures

Ethical Permission: The proposal of the study was in Yasouj University of Medical Sciences committee and approved by ethic code: IR.REC.1396.92.

Conflict of Interests: The authors declare no conflict of interest.

Authors' Contribution: Rabani SM. (First author), Introduction author/ Methodologist/ Original researcher (60\%); Mousavizadeh A. (Second author), Statistical analyst (15\%); Rabani SH. (Third author), Assistant/ Discussion author (13\%);
Mousavi A. (Fourth author), Assistant/ Discussion author (12\%)

Funding: This research has not been sponsored by funding source.

\section{References}

1- Bossio JA, Pukall CF, Steele S. A review of the current state of the male circumcision literature. J Sex Med. 2014;11(12):2847-64.

2- Ahmad A. do motives matter in male circumcision? 'Conscientious objection' against the circumcision of a Muslim child with a blood disorder. Bioethics. 2014;28(2):67-75.

3- Hayford SR, Trinitapoli J. Religious differences in female genital cutting: a case study from Burkina Faso. J Sci Study Relig. 2011;50(2):252-71.

4- Williams N, Kapila L. Complications of circumcision. Br J Surg. 1993;80(10):1231-6.

5- Abdulwahab-Ahmed A, Mungadi IA. Techniques of male circumcision. J Surg Tech Case Rep. 2013;5(1):1-7.

6- Anike U, Govender I, Ndimande JV, Tumbo J. Complications of traditional circumcision amongst young Xhosa males seen at St Lucy's Hospital, Tsolo, Eastern Cape, South Africa. Afr J Prim Health Care Fam Med. 2013;5(1):488.

7- Fox M, Thomson M. The new politics of male circumcision: HIV/AIDS, health law and social justice. Leg Stud. 2012;32(2):255-81.

8- Brusa M, Barilan YM. Cultural circumcision in EU public hospitals - an ethical discussion. Bioethics. 2009;23(8):470-82.

9- Frisch M, Lindholm M, Gronbeck M. Male circumcision and sexual function in men and women: a survey-based, cross-sectional study in Denmark. Int J Epidemiol. 2011;40(5):1367-81.

10- Lyons B. Male infant circumcision as a 'HIV vaccine'. Public Health Ethics. 2013;6(1):90-103.

11- Mielke RT. Counseling parents who are considering newborn male circumcision. J Midwifery Womens Health. 2013;58(6):671-82. 